\title{
Carcinoma oat-cell de esófago: presentación de dos casos y actualización bibliográfica
}

\author{
A. Liñán Padilla, A. Milla Sabas, J. M. Abad Zamora, A. Vázquez Medina, F. Ibáñez, F. Alcántara \\ y J. M. Hernández de la Torre \\ Departamento de Cirugía Esofágica y de Tracto Digestivo Superior. Hospitales Universitarios Virgen del Rocío. Sevilla
}

\section{RESUMEN}

Objetivo: nuestro objetivo es aportar una visión actualizada sobre una patología tan infrecuente como el carcinoma oat-cell esofágico, mediante revisión de la bibliografía y la exposición de dos casos de reciente aparición en nuestro servicio.

Material y método: se realizó un estudio retrospectivo con revisión de las historias clínicas de los pacientes ingresados en nuestro servicio con el diagnóstico de neoplasia esofágica en los últimos 6 años (enero de 2000 a diciembre de 2006).

Resultados: se estudiaron 249 casos de neoplasias de esófago en el curso de este periodo de 6 años, de ellas 106 fueron de estirpe epidermoide (42,6\%), 141 adenocarcinomas (56,6\%) y 2 oat-cell (0,8\%). Del total de estos tumores sólo en $45(18 \%)$ de ellos se pudo realizar resección quirúrgica, en 23 (9,3\%) cirugía paliativa (no se incluyen prótesis endoscópicas, gastrostomías ni yeyunostomías) y en el resto (181 casos, 72,7\%) cirugía derivativa o ninguna opción quirúrgica.

Conclusiones: podemos afirmar que esta neoplasia es altamente agresiva, presentando en prácticamente la totalidad de los casos diseminación a otras localizaciones. Se trata de un cáncer muy poco frecuente que afecta mayoritariamente a varones y cuya clínica es similar al resto de procesos neoplásicos que afectan al esófago.

Palabras clave: Carcinoma de célula pequeña. Esófago. Oat-cell.

\begin{abstract}
Objective: our objective is to contribute an updated view on a condition as rare as oat-cell carcinoma of the esophagus by reviewing the literature and reporting two recent patients seen in our department.

Material and method: a retrospective study with a review of all medical records of patients seen in our ward and diagnosed with esophageal neoplasm for 6 years (January 2000 to December 2006).

Results: 249 cases of esophageal neoplasms were found, of them 106 were of squamous ancestry (42.6\%), 141 were adenocarcinomas (56.6\%), and 2 were oat-cell carcinomas (0.8\%). Only in $45(18 \%)$ was surgical resection feasible, 23 underwent palliative surgery (endoprostheses, gastrostomies, and jejunostomies not included) (9.3\%), and the rest (181 cases, $72.7 \%)$ received derivative surgery or no surgery at all.

Conclusions: we can affirm that this neoplasm is highly aggressive, displaying in practically all cases dissemination to other sites; this is a rare cancer that mainly affects men and whose clinical picture is similar to that of other malignancies involving the esophagus.
\end{abstract}

Key words: Small-cell carcinoma. Esophagus. Oat-cell carcinoma.

Liñán Padilla A, Milla Sabas A, Abad Zamora JM, Vázquez Medina A, Ibáñez F, Alcántara F, Hernández de la Torre JM. Carcinoma oat-cell de esófago: presentación de dos casos y actualización bibliográfica. Rev Esp Enferm Dig 2007; 99: 415-419.

\section{INTRODUCCIÓN}

Los tumores neuroendocrinos de células pequeñas (tipo "oat-cell"), suponen una variedad histológica de neoplasia cuya presentación principal es a nivel pulmonar, representando el $20-25 \%$ de todos los tumores malignos pulmona-

Recibido: 23-02-07.

Aceptado: 27-02-07.

Correspondencia: Alejandro Liñán Padilla. C/ Antonio Filpo Rojas, 14, $1^{\circ}$ izda. 41008 Sevilla. e-mail: linan_alejandro@hotmail.com res $(1,2)$. La localización extrapulmonar es muy infrecuente, aunque sí se han descrito en diversas localizaciones: miocardio, pericardio, sistema nervioso central, vejiga urinaria, próstata y en tracto digestivo, siendo el esófago con diferencia el asiento en aparato digestivo más frecuente, aunque también se dan en área colorrectal, estómago, páncreas, intestino delgado y vía biliar principal $(2,3)$.

Todos comparten una característica fundamental, que es su gran agresividad y mal pronóstico, con metástasis en aproximadamente la mitad de los casos en el momento del diagnóstico (4). 
El oat-cell esofágico representa, según las series, entre un 1 y un $2,8 \%$ de los casos de cáncer de esófago, llegando hasta un $9 \%$ en Japón. Se trata de una enfermedad rara de tal modo que desde su primera descripción en 1952 por Mac Keown no se han registrado en el mundo más de 300 casos $(3,5)$.

La manifestación clínica es idéntica a la de cualquier extirpe de cáncer de esófago, siendo la disfagia el síntoma principal, y variablemente un cuadro consuntivo asociado. No existe posibilidad de tratamiento estándar, habiéndose descrito diversas pautas quirúrgicas, médicas oncológicas (quimioterapia y radioterapia) o asociadas.

\section{MÉTODOS Y RESULTADOS}

\section{Caso clínico 1}

Varón de 72 años, como antecedentes: exfumador (desde hace 17 años), bebedor moderado y EPOC en tratamiento; remitido desde el Servicio de Digestivo por estudio de disfagia a sólidos y líquidos con anorexia y pérdida de peso progresiva.

Se procede a estudio con endoscopia oral informando de la existencia de una masa mamelonada y estenosante desde los $32 \mathrm{~cm}$ a unión esofagogástrica, en la que se observa orificio fistuloso, desconociéndose el trayecto y su extremo distal; en la biopsia se halla tan sólo el componente epidermoide de la neoplasia moderadamente diferenciado, ulcerado e infiltrante. La TAC toraco-abdominal (Fig. 1), muestra un engrosamiento de la pared esofágica en tercio inferior y unión esófago gástrica, en cuya porción caudal queda una pequeña luz filiforme, sin identificarse el trayecto fistuloso reseñado; sin afectación mediastínica ni de órganos abdominales. El estudio esofagogastroduodenal baritado, revela estenosis de $1-5 \mathrm{~cm}$ de longitud en el tercio inferior de esófago (Fig. 2), sin

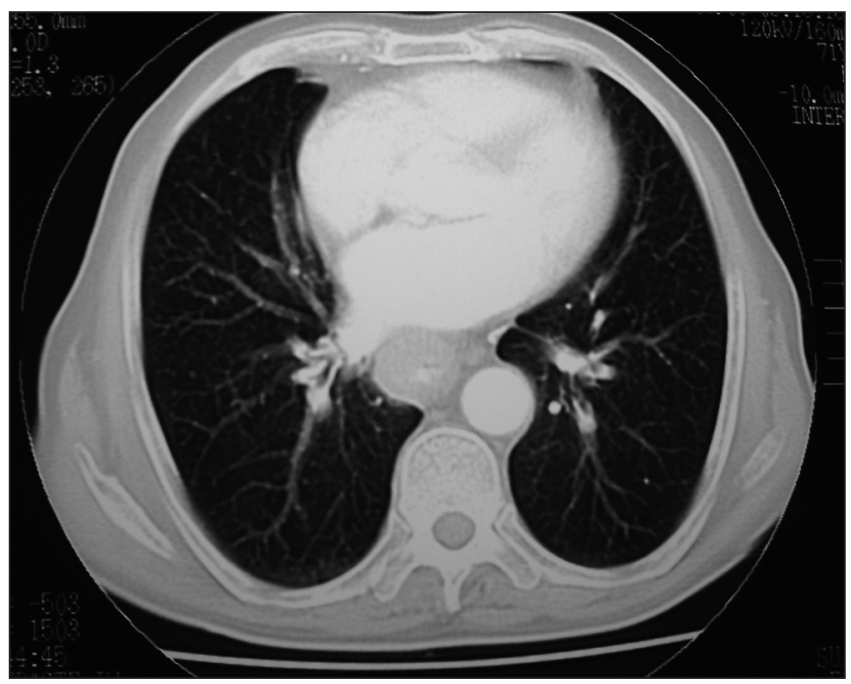

Fig. 1. TAC toraco-abdominal en el que se aprecia engrosamiento estenosante de la pared esofágica.

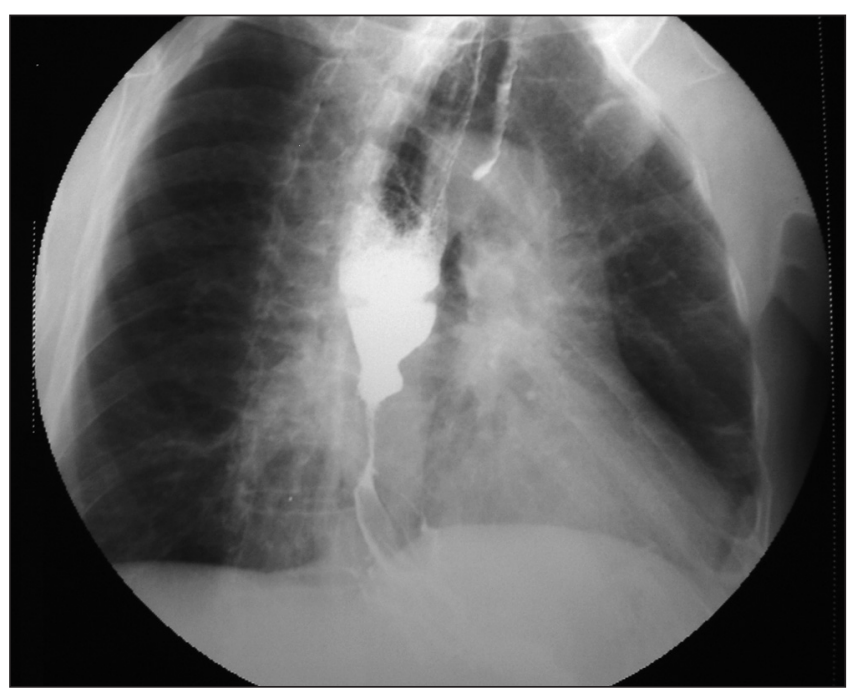

Fig. 2. Estudio baritado que muestra estenosis en tercio distal de esófago.

otros hallazgos relevantes. La ecoendoscopia muestra una lesión que afecta a todas las capas de la pared esofágica que se inicia inmediatamente a nivel subcarinal, extendiéndose hacia el borde izquierdo en el que algún punto sobrepasa la adventicia, penetrando mínimamente en grasa periesofágica; contactando con aorta y pleura derecha, sin llegar a invadirla; desde el punto de vista ganglionar sólo se observaba una pequeña adenopatía subcarinal de aspecto inflamatoria (T3N0).

Se procedió a realización de esofaguectomía, gastroplastia intratorácica y yeyunostomía de alimentación.

El estudio anatomopatológico de la pieza quirúrgica, mostró un cáncer infiltrante de $5 \mathrm{~cm}$ con componente epidermoide bien diferenciado y microcítico, con 2 adenopatías aisladas con claro predominio del componente microcítico y afectación del borde circunferencial.

Fue sometido posteriormente a tratamiento adyuvante quimioterápico (carboplatino, etopósido) y radioterapia $(60 G y)$. A los 10 meses del diagnóstico se repitió la TAC que mostró imágenes compatibles con metástasis hepáticas, que obligó a iniciar quimioterapia paliativa con etopósido que en la actualidad continúa recibiendo.

\section{Caso clínico 2}

Mujer de 68 años, como antecedentes personales de interés refiere ser fumadora de 20 cigarrillos/día desde hace 40 años, y como intervenciones quirúrgicas: colecistectomía, amigdalectomía y anexectomía bilateral (por polimiomatosis uterina). Estudiada dos años atrás en consultas de digestivo por una disfagia moderada a sólidos, sin otra sintomatología acompañante, se realiza endoscopia digestiva alta con hallazgo de una hernia de hiato, recomendándose tratamiento con inhibidores de la bomba de protones, con mejora considerable de los síntomas. Posteriormente y durante el periodo de revisión en con- 
sultas, presenta un cuadro de dolor epigástrico intenso de unos meses de evolución, por lo que se repite una segunda endoscopia en la que se evidencia una lesión a nivel de tercio medio de esófago, biopsiada e informada como carcinoma de célula pequeña tipo "oat-cell" ulcerado e infiltrante. Ante estos hallazgos, se procede a completar estudios en la paciente realizándose distintas exploraciones con el objetivo fundamental de encontrar el tumor primario (pensando en un origen pulmonar dado la especie histológica de la neoplasia) y estadiar la enfermedad.

A la exploración la paciente presentaba un estado general conservado, afebril, sin hallazgos de adenopatías, ni datos relevantes en la auscultación cardiopulmonar, con abdomen normal salvo la cicatriz subcostal derecha e infraumbilical continentes y sin presentar alteraciones a nivel neurológico.

A nivel analítico no presentaba alteración alguna relevante. El estudio esofagogastroduodenal baritado mostró a $5 \mathrm{~cm}$ de la unión esofagogástrica una lesión plana y ulcerada de unos $5 \mathrm{~cm}$ de longitud que reducía discretamente la luz del mismo, siendo el resto del estudio normal (Fig. 3).

En la TAC toraco-abdominal se observa una neoplasia a nivel del tercio medio esofágico, que provoca disminución de su luz, con adenopatías en el área subcarinal, supraclavicular izquierda (1,5 cm); en abdomen adenopatías en retroperitoneo, área retrocrural y cadena iliaca derecha; imágenes sugestivas de metástasis hepáticas bilobulares y un gran quiste esplénico (Fig. 4). No se evidencia lesión ocupante de espacio a nivel pulmonar. En la fibrobroncoscopia no se encontraron hallazgos patológicos. Se realizó un aspirado de punción transtorácica con positividad para carcinoma tipo oat-cell, que podría indicar invasión pleural.

La ecoendoscopia mostró una tumoración esofágica vegetante y ulcerada, que se extendía desde los 30 a 35

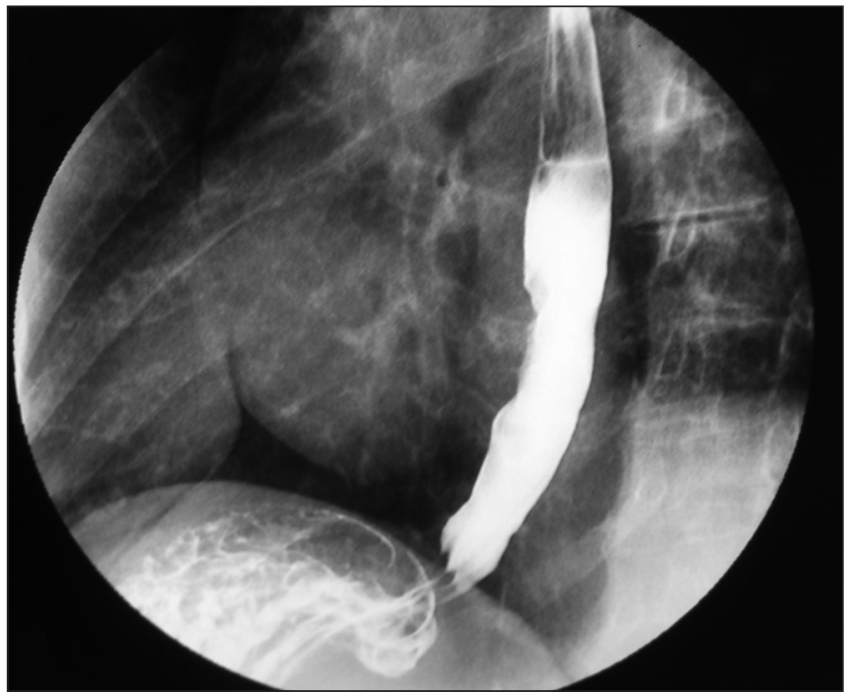

Fig. 3. Lesión ulcerada que reduce mínimamente la luz esofágica en el estudio baritado.

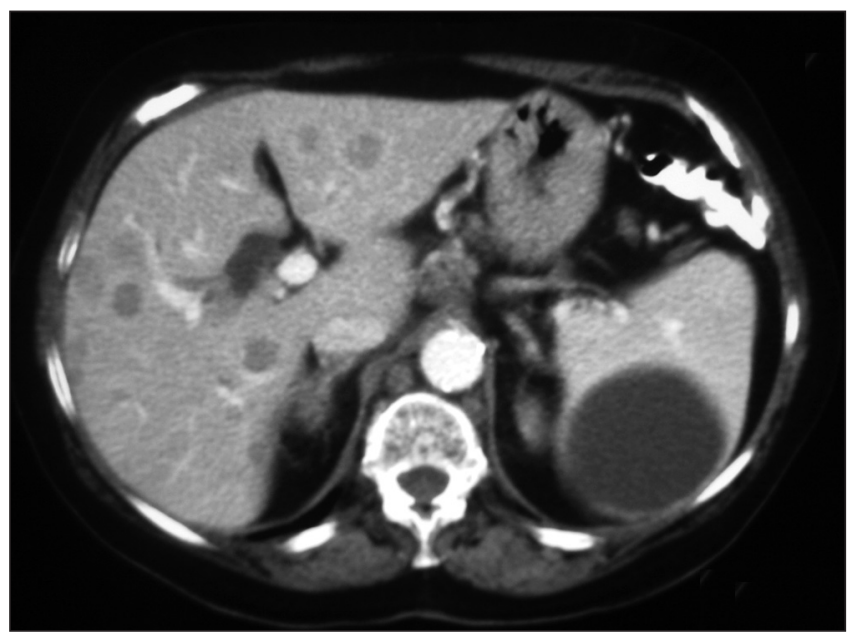

Fig. 4. Imagen de TAC de múltiples metástasis hepáticas en ambos lóbulos.

cm y que infiltraba las $2 / 3$ partes de sus caras, pero que permitía el paso del endoscopio. Entre los 28 y $32 \mathrm{~cm}$ había una masa extrínseca retrocardiaca bien delimitada y que no infiltraba esófago. Se hallaron múltiples adenopatías celiacas. Y la biopsia de la lesión se informa como carcinoma de células pequeñas tipo oat-cell. La TAC craneal no demostró ningún hallazgo patológico.

Dada la extensión de la neoplasia, se desestima la cirugía, pensándose en la quimioterapia como principal opción terapéutica estando, a la finalización del presente trabajo, en tratamiento en la Unidad de Oncología de nuestro hospital (esquema con CDDP más etopósido).

\section{DISCUSIÓN}

El carcinoma oat-cell esofágico es una entidad histológica de escasa incidencia, lo que dificulta la realización de estudios prospectivos, siendo esta la localización extrapulmonar más frecuente. El término de oat-cell es probablemente el más utilizado, aunque no el único, pues hay otras denominaciones que comprenden la misma entidad: microcitoma, carcinoma indiferenciado, carcinoma anaplásico, carcinoma de células de Kultchisky... Del mismo modo si entendemos que esta neoplasia procede de una extirpe celular pluripotencial, ello explica que en ocasiones se encuentre un "oat-cell" puro y en otras coexista con diversas diferenciaciones celulares, preferentemente epidermoide (6). Esto hace que nos planteemos algunas cuestiones; cuántos de aquellos casos informados histológicamente indiferenciados son o pueden ser de células pequeñas, del mismo modo que aquellos adenocarcinomas o epidermoides poco diferenciados, en los que apreciamos una evolución fatal y demasiado rápida, no esperable para esta clase de tumores, si no se tratarían en realidad de microcíticos no objetivados desde Anatomía Patológica. Por otro lado, podríamos preguntarnos si 
aquellos clasificados como oat-cell primarios de esofágo son realmente tales y no metástasis de una neoplasia pulmonar, que no alcanza tamaño suficiente para ser detectada en las distintas pruebas de imagen.

La incidencia de este tipo de tumor es realmente baja variando según series, en nuestra Unidad de Cirugía de Esófago y Tracto Digestivo Superior en la que se atiende a una media de 40 cánceres de esófago al año de los cuales más de la mitad acaban interviniéndose, tan sólo se han recogido 2 casos de oat-cell en los últimos 6 años, lo que supondría una incidencia aproximada de un $0,8 \%$. Si bien parece aceptada una incidencia de entre $1-2,8 \%$, hay casos en la bibliografía con una incidencia sensiblemente inferior, como las de la serie de la TATA Memorial Hospital Experience con una cifra escasa de $0,15 \%$ (4).

La proporción de este tumor es de 2:1 para el sexo masculino; apareciendo fundamentalmente entre la sexta y octava décadas de la vida. Los principales síntomas son disfagia, rápidamente progresiva y pérdida de peso (al igual que el resto de tumores esofágicos). Afecta casi exclusivamente al tercio medio e inferior del esófago (7). El diagnóstico es casi siempre muy tardío (con metástasis en el momento del diagnóstico en la mitad de los casos) $(7,8)$, presentándose con gran agresividad, y su pronóstico es realmente sombrío, con una supervivencia media de 7-8 meses (9); aunque excepcionalmente, se registra algún caso de supervivencia elevada de hasta 37 meses (10). Hay un importante trabajo publicado por Casas y cols., en el que los autores de una extensa muestra de 199 pacientes con carcinoma de esófago microcítico evalúan los factores pronósticos que influyen en la supervivencia, siendo de todos ellos el más determinante, la extensión de la enfermedad en el momento del diagnóstico, si se trataba de una enfermedad localizada (para los que halló una supervivencia media de 8 meses) o extendida (3 meses). También consideraron otros factores como la edad, el tamaño del tumor o el tipo de tratamiento recibido (11).

Por ello, pensamos que hay dos exploraciones que podrían hacer un mejor estadiaje preoperatorio: la ecoendoscopia, pues nos informa acerca de la profundidad en la infiltración de la pared esofágica y estructuras adyacentes, las dimensiones de la neoplasia primaria y la existencia o no de adenopatías a nivel mediastínico (aunque no sirve para descartar la existencia de metástasis sistémicas, para lo que la TAC continúa siendo la mejor prueba complementaria); y la PET (tomografía con emisión de positrones), que puede revelar imágenes de depósito patológico tanto a nivel local como locorregional o a distancia que podrían no ser visualizadas en la TAC. Además nos puede ayudar a declarar aún con más fundamento que se trata de un cáncer primariamente esofágico y descartar así un posible origen primario pulmonar, ya que como hemos comentado dada la rareza de esta estirpe tumoral, siempre nos pueden quedar dudas acerca del verdadero origen del tumor.
El patrón de diseminación habitual de estos tumores, que también han seguido nuestros dos casos, es el que sigue a continuación: en el momento del diagnóstico están presentes casi de manera constante adenopatías locorregionales y metástasis a distancia en la mitad de los casos, con una secuencia de depósito más o menos ordenada que podría ser hígado, ganglios a distancia, huesos, médula ósea, pulmón, piel y cerebro.

En lo referente al mejor tratamiento para esta entidad hay gran controversia, tanto por las propias particularidades del tumor como por la ausencia de estudios relevantes para dar recomendaciones concretas con fundamento. Dado el avanzado estado de la enfermedad en el momento del diagnóstico y la elevada agresividad de la misma, parece claro que las necesidades de tratamiento médico quimioterápico son prácticamente universales a todos los casos (11), estableciéndose supervivencias variables de meses, según lo avanzado de la enfermedad, en oposición a las escasas semanas de aquellos pacientes que no han recibido tratamiento alguno (12). Se trata de un tumor quimiosensible, en el que se aprecia frecuentemente muy buena respuesta inicial, incluso con desaparición evidente de lesiones en los estudios de imagen, pero que al poco tiempo recidiva con gran virulencia, hacia un fatal desenlace $(2,13)$. En los esquemas quimioterápicos son varios los fármacos empleados (etopósido, doxorubicina, vincristina, bleomicina...) siendo la combinación de cisplatino y etopósido la más empleada en la actualidad (14) (al igual que en el oat-cell pulmonar).

La cirugía no supone la principal opción terapéutica, mas que en los casos de enfermedad localizada en los que sí se debe plantear una cirugía con intención curativa (14). En el resto de los casos probablemente se trate de una indicación con fines paliativos, agotadas antes las posibilidades que supongan una menor agresión, como son las endoprótesis esofágicas por vía endoscópica. Sin embargo, hemos de considerar que los casos que han registrado unas supervivencias mayores han recibido una terapeútica conjunta que incluía esofaguectomía combinada con quimio- o radioterapia (15). El papel de la radioterapia no está bien definido, y probablemente se pueda ceñir a casos, como los citados anteriormente, de estadios localizados en combinación con la cirugía.

\section{BIBLIOGRAFÍA}

1. García Fontgivell JF, Blázquez Vilàs S, Mayayo Artal E. Carcinoma de célula pequeña pulmonar combinado con adenocarcinoma y carcinoma escamoso. Rev Española Patología 2005; 38 (3).

2. Kim JH, Lee SH, Park J, et al. Extrapulmonary small-cell carcinoma: A single institution experience. Jpn J Clin Oncol 2004; 34 (5): 250-4.

3. Brenner B, Tang HL, Klimstrad DS, Kelsen DP. Small-cell carcinomas of the gastrointestinal tract: A review. J Clin Oncol 2004; 22 (13): 2730-9.

4. Pantvaidya GH, Pramesh CS, Deshpande MS, Jambhekar NA, Sharma S, Deshpande RK. Small cell carcinoma of the esophagus: The Tata Memorial Hospital Experience. Ann Thorac Surg 2002; 74: 1924-7. 
5. Shimoda T, Koizumi W, Tanabe S, Higuchi K, Sasaki T, Nakayama $\mathrm{N}$, et al. Small cell carcinoma of the esophagus associated with a paraneoplastic neurological syndrome: A case report documenting a complete response. Jpn J Clin Oncol 2006; 36 (2): 109-12.

6. Ho KJ, Herrera GA, Jones JM, Alexander CB. Small cell carcinoma of the esophagus: Evidence for a unified histogenesis. Hum Pathol 1984; 15: 460

7. Law SY, Fok M, Lam KY, et al. Small cell carcinoma of the esophagus. Cancer 1994; 73: 2894.

8. Isolauri J, Mattila J, Kallionemi OP. Primary undifferentiated small cell carcinoma of the esophagus: Clinicopathological and flow cytometric evaluation of eight cases. J Surg Oncol 1991; 46: 174-7.

9. Mc Fadden DW, Rudnicki M, Talamini MA. Primary small cell carcinoma of the esophagus. Ann Thorac Surg 1989; 47: 475-80.

10. Wu Z, Ma JY, Yang JJ, Zhao YF, Zhang SF. Primary small cell carcinoma of esophagus: Report of nine cases and review of literature. World J Gastroenterol 2004; 10 (24): 3680-2.
11. Casas F, Ferrer F, Farrus B, Casals J, Biete A. Primary small cell carcinoma of esophagus: A review of the literature with emphasis on therapy and prognosis. Cancer 1997; 80: 1366-72.

12. Huncharek M. Long-term survival associated with metastatic small cell carcinoma of the esophagus treated by chemotherapy, autologous bone marrow transplantation, and adjuvant radiation therapy. Cancer 1994; 74: 217.

13. Sengoz M, Abacioglu U, Salepci T, et al. Extrapulmonary small cell carcinoma: multimodality treatment results. Tumori 2003; 89: 274

14. Hoff PM, Pazdur R, Raghavan D, Brecher M, Johnson DH, et al. Small cell carcinoma of the gastrointestinal tract: Textbook of uncommon cancer (Ed 2), West Sussex, UK, Wiley and Sons Ltd; 1999. p. 463-7.

15. Medgyesy CD, Wolff RA, Putnam JB Jr, Ajani JA. Small cell carcinoma of the esophagus: the University of Texas M. D. Anderson Cancer Center Experience and literature review. Cancer 2000; 88: 262-7. 